\title{
Outpatient Error in Perception of Medication; is it a Miscommunication Problem?
}

\author{
Zainah J, Marina I, Asrina A, Kanmani M and Asma’ A
}

KPJ Seremban Specialist Hospital, Seremban, Negeri Sembilan

\begin{abstract}
Introduction: The NCC for Medication Error defines it as any preventable event that may lead to inappropriate medication use or patient harm while the medication is in control of the healthcare professionals, patients or consumers. The annual cost of drug related morbidity and mortality is US $\$ 177$ billion in America. The FDA states that one death per day and 1.3 million people were injured yearly due to medication error. The objectives of this study were to comply with patients' safety goals, to achieve zero medication error and to ensure compliance among outpatients. Materials and Methods: All outpatients' prescriptions were analyzed prospectively from January to December 2009. The data were categorized according to incomplete prescription, inappropriate drug regimen, illegibility and wrong administration to patients. We introduced a coloured labeling system to improve patient understanding of medication administration routes and frequency. Results: Data analysis between January and May 2009 showed medication error in outpatients was high. By doing root-cause analysis, we identified the main cause of medication error was miscommunication between pharmacist and outpatients. To correct this error, visual reinforcement on the routes of administration was done to enable patients to better understand the right administration of medications. From June to October 2009 post implementation showed reduction of medication error from $1.34 \%$ to $0.82 \%$. Zero medication error was achieved in the last two months. Feedback from patients revealed that $88.2 \%$ agreed poor labeling was the main cause of wrong administration of drugs at home. Conclusion: Although studies had been done on inpatient medication errors, we had no data over outpatients' prescription trends. Although this study was simple, yet by creating multi-colored labels which were user friendly we have shown that outpatients' medication error can be rectified.
\end{abstract}

KEYWORDS: Prescription, error, labeling

Corresponding author;

Zainah J

KPJ Seremban Specialist Hospital, Lot 6219 \& 6220, Jalan Toman Satu, Kemayan Square,

70200 Seremban, Negeri Sembilan

e-mail: zainah@ssh.kpjhealth.com.my 


\title{
Severe Oro-laryngeal Thrush Following Excessive Use of Steroid Inhaler
}

\author{
Marina $\mathrm{MB}^{\mathrm{a}}$, Ramli $\mathrm{R}^{\mathrm{b}}$ and Primuharsa Putra SHAc \\ ${ }^{a}$ Department of Otorhinolaryngology-Head \& Neck Surgery, ${ }^{b}$ Department of Oral \& Maxillofacial Surgery, \\ Universiti Kebangsaan Malaysia Medical Centre, 'Ear, Nose \& Throat - Head \& Neck Consultant Clinic, KPJ \\ Seremban Specialist Hospital
}

\begin{abstract}
Introduction: Inhaled steroids such as fluticasone propionate and beclomethasone dipropionate play an important role in the treatment of bronchial asthma. Its usage facilitates disease control in asthmatic patients, resulting in improved quality of life. Because of its benefit, the inhaled steroid is used extensively, at higher doses and for longer duration. However, the localized effects of inhaled corticosteroids on oral/laryngeal mucosa, such as fungal infections can be problematic. Case Report: We report a case of oropharyngeal and laryngeal candidiasis following a long period and high doses of inhaled steroid in a 42-year-old male. He presented with a complaint of increasing tiredness, phlegm, intermittent wheezing and hoarseness for 2-3 months. There was no weight loss or loss of appetite. He has been using inhaled steroids and long acting bronchodilators in increasing doses for his claimed 'wheezing' despite the negative history of asthma. The inhaled steroids were fluticasone dipropionate at doses of 500-100 mcg daily for 2-3 months. Results: Examination revealed widespread oral thrush involving the oral cavity, oropharynx and larynx. There was no cushingoid habitus. His muscle power was of 5/5 bilaterally and his lungs were clear. Lung function and chest film were also normal. The steroid was stopped immediately and flucanozole and nystatin syrup were prescribed. The patient made an uneventful and complete recovery. Conclusion: We conclude that patients on inhaled corticosteroids should be monitored for local side effects. Physicians should be aware not only of the systemic but also of the local side effects of inhaled corticosteroids. Patients may increase doses without the knowledge of their physicians and subsequently suffer the adverse effects either local or systemic.
\end{abstract}

KEYWORDS: Oro-laryngeal, candidiasis, thrush

Corresponding author;

Dr Primuharsa Putra

KPJ Seremban Specialist Hospital, Lot 6219 \& 6220,

Jalan Toman Satu, Kemayan Square,

70200 Seremban, Negeri Sembilan

e-mail: putrani@yahoo.co.uk,

primuharsa.putra@gmail.com 


\title{
Left Vocal Cord Paralysis Secondary to Mitral Valve Disease
}

\author{
Marina $\mathrm{MB}^{\mathrm{a}}$ and Primuharsa Putra SHA \\ ${ }^{a}$ Department of Otorhinolaryngology-Head \& Neck Surgery, Universiti Kebangsaan Malaysia Medical Centre, \\ ${ }^{b}$ Ear, Nose \& Throat-Head \& Neck Consultant Clinic, KPJ Seremban Specialist Hospital
}

\begin{abstract}
Introduction: Ortner's syndrome, or cardio-vocal syndrome, is a clinical entity characterised by hoarseness (secondary to left-sided recurrent laryngeal nerve palsy) caused by cardiovascular disease. The incidence of Ortner's syndrome ranges from 0.25 percent to 0.5 percent of all cases of recurrent laryngeal nerve paralysis. Case Report: A 44-year-old Malay gentleman presented with hoarseness and shortness of breath for 4 days. It was associated with mild orthopnea and aspiration symptoms. He denied history of dysphagia, chronic cough, sore throat, chest pain, palpitation and decreased effort tolerance. There was no history of hypertension, diabetes and asthma. He also gave no history of recurrent fever with sore throat during childhood. Results: On examination, the patient appeared tachypnoeic. There was no peripheral oedema, cyanosis or clubbing. His blood pressure was $100 / 60 \mathrm{~mm} \mathrm{Hg}$ and his pulse was irregular with a rate of $78 / \mathrm{min}$. Neck examination was normal. Apex beat was not displaced. On auscultation the first heart sound was loud. A grade 3/6 long rumbling diastolic murmur was heard at the mitral area and he had bilateral basal crepitations. Laryngoscopy using 700 scope showed left vocal cord palsy in paramedian position with phonatory gap. Computed tomography (CT) of the thorax showed left atrial enlargement with prominent pulmonary veins. Echochardiography showed left atrial dilatation with thickened mitral valve. Left ventricular systolic function was good with ejection fraction of $70 \%$ and coronary angiogram showed normal coronary artery. A diagnosis of severe mitral stenosis with heart failure was made. Preoperatively the patient was stabilized and was referred for dental clearance. Then he underwent surgery for mitral and aortic valve replacement. Post-operatively patient recovered uneventfully. His hoarseness recovered completely after 3 months. Conclusion: Cardiovascular disease should be considered as a differential diagnosis in a patient with hoarseness.
\end{abstract}

KEYWORDS: Mitral valve, Ortner's syndrome, hoarseness

Corresponding author;

Dr Primuharsa Putra

KPJ Seremban Specialist Hospital, Lot 6219 \& 6220,

Jalan Toman Satu, Kemayan Square,

70200 Seremban, Negeri Sembilan

e-mail: putrani@yahoo.co.uk, primuharsa.putra@gmail.com 


\title{
Intervention to Reduce Needle Stick Injuries
}

\author{
Tun Fizi A, Maygala A, Suzana K, Yogeswari A, Nishazini MB and Zainah J \\ KPJ Seremban Specialist Hospital, Seremban, Negeri Sembilan
}

\section{ABSTRACT}

Introduction: Healthcare workers face the risk of infection from potentially deadly diseases from the use of unsafe needles every day. It has been estimated that over 350,000 needlestick and sharps related injuries occur annually with an average of 1,000 infections annually and over 100 deaths by the CDC (Centers for Disease Control \& Prevention). It has been reported that 0.6 cases in average of needle stick injury incident occurred in KPJ Seremban almost every month in 2008. Analysis was done and it was that found that the majority of cases were due to failure to adhere to universal precautions. Materials and Methods: A retrospective study was done (January to December 2008). Data was collected from reviewed incidence reports. Statistics showed that needle stick injuries occurred after a procedure and during disposal of used needles. We then introduced several measures with these aims; to inculcate 'Safety Culture' among healthcare workers through quality training, to ensure that all newly qualified healthcare workers are well trained in handling sharp devices, to reduce the incidence of needlestick injuries, to do effective monitoring audit, to convey knowledge to healthcare workers on safety practices by Infection control team. These strategies included; High quality education and training to all staffs conducted continuously, identifying those at risk, introduce safer medical devices - using of Angiocath for setting IV line and needle-less injection port and providing for a secure work environment. Results: 1) Needle stick injury cases reduce 65\% as compared to last year. 2) Through surveys and questionnaires, 95\% of healthcare workers understand and adhere to universal precautions in 2009 as compared 30\% in previous year. 3) Number training conducted increased from 7days in year 2008 to 21 days in year 2009. Conclusion: Collaborative and participative approaches are helpful in reducing the transmission of blood borne pathogens and other sharps-related injuries.

KEYWORDS: Needle-stick injury, prevention, strategies

Corresponding author; Nishazini bt Mohd Basir, Quality Assurance Officer KPJ Seremban Specialist Hospital, Lot 6219 \& 6220, Jalan Toman Satu, Kemayan Square, 70200 Seremban, Negeri Sembilan e-mail: nisha@ssh.kpjhealth.com.my 


\title{
A 5-year review of malaria surveillance in Kuching, Sarawak
}

\author{
Haironi Y and Kamaliah MD \\ Dept of Community Med \& Public Health, Faculty of Medicine \& Health Sciences, Universiti Malaysia Sarawak
}

\begin{abstract}
Introduction: Malaria is endemic in Sarawak contributing to the highest incidence rate in Malaysia. Kuching division consists of three main areas, namely Kuching district, Lundu and Bau. This review aims to highlight the trends of malaria over the past five years in terms of demographic characteristics and vector control programmes and to identify factors that contribute to the difficulty in malaria control programme in this state. Materials and Methods: This is a descriptive review of malaria cases based on surveillance data compiled from 2000 to 2004. Data is analysed based on demographic background, malaria species, type of malaria infection and vector control activities between the three districts. Results: Lundu has the highest average 5-year incidence rate per 10,000 population of 121.97 as compared to the national figure of 4.10. Malaria is more prevalent in males (14.3\%) than females (5.7\%). Among the race, Dayaks had the highest prevalence rate (66.5\%). Peak age affected is between 15 to 40 years. The predominant species was Plasmodium vivax (65.4\%) followed by Plasmodium falciparum (32.8\%). For occupation, the majority of cases were among villagers (55.2\%) followed by foreign workers (19.0\%). Cases were detected mainly by passive case detection (82.7\%) and blood film for malarial parasites was positive in $2.67 \%$. For malaria control activities, focal spraying were successfully done in $94.4 \%$ of the structures, regular spraying in $89.5 \%$ structures, impregnated bednet distribution among $38.2 \%$ population and mass drug administration distributed among $\mathbf{8 0 . 7 \%}$ of the population. Conclusion: Results analysis has shown that the incidence rate of malaria in Kuching division is very high, particularly in Lundu district. Although activities conducted by the malaria control programme is sufficient, it has not been able to successfully reduce the incidence of malaria in this region. Problems identified include difficulty in accessing the affected areas, movements of illegal immigrants, financial constraints and lack of training of field staff involved in malaria control. Recommendations include integrating malaria control measures with cross border agents, community participation, aggressive surveillance programmes and improvement of vector control.
\end{abstract}

KEYWORDS: Review, malaria, prevalence 


\title{
Performance of the Final Year Medical Students - Universiti Malaysia Sabah in the End Surgical Senior Posting (SSP) Examination.
}

Basim AMHA ${ }^{\mathrm{a}}$ and Chee $\mathrm{FT}^{\mathrm{b}}$

${ }^{a}$ Department of Surgery, School of Medicine, ${ }^{b}$ School of Sustainable Agriculture, Universiti Malaysia Sabah

\begin{abstract}
Introduction: Assessment methods are used to provide students with both formal and informal feedback on their progress, and should be congruent with the objectives of the curriculum. To achieve this, it is necessary to bring the theories of learning and assessment together. Senior surgical posting is an intensive eight weeks attachment with overall surgical revision, provide an opportunity for the students to develop clinical skills, knowledge and attitudes, at it's end the students will be evaluated through three forms of assessment, their knowledge by MCQs, MEQs, and essay and their clinical skills by OSCE, short case and long case examination together with that there was continues assessment (log book and two handwritten case reports), the passing marks is 65 of 100, and passing the clinical section is mandatory. Materials and Methods: This paper studied the performance of final year (Year 5) medical students Universiti Malaysia Sabah (UMS)-school of medicine in the end senior surgical posting examination. Results and Conclusion: Through analysis of the data of their assessment results in this examination, it shows that the continuous assessment have strong effect on the final results of the students, and students have defect in theory back ground reflected by their poor MCQs performance, and the mode of UMS students learning is more towards deep approach.
\end{abstract}

KEYWORDS: Clinical-assessment, performance-assessment, senior surgical posting

Corresponding author;

Basim A. M. H. Almothafar

Department of Surgery, School of Medicine,

Universiti Malaysia Sabah

Locked Bag 2073, 88999 Kota Kinabalu, Sabah

e-mail: basim_amh@yahoo.com 


\title{
Predicting Falls Risk in Hospital; KPJ Seremban Experience
}

\author{
Maygala A, Primuhasa Putra SHA, Aziz AR, Ainol MR, Zainah J, Asrina A, Suzana K, Zainab MN, Nisha MB
}

KPJ Seremban Specialist Hospital, Seremban, Negeri Sembilan

\begin{abstract}
Introduction: Falls may result in injuries, prolonged hospitalization, increase in morbidity and mortality, incur cost to the individual and the healthcare system and increase potential litigation. Various hospital fall prevention programs such as Morse Fall Scale Assessment Tool have been implemented in the last decade; however most of the program had no sustained effects on falls reduction over extended period of time. Benchmarking from private hospitals showed patients fall increased by 27\% in 2008 as compared to 2007 (MPC report, 2008). There were 25 cases of falls in 2008 at KPJ Seremban Specialist Hospital. The objective of this program is to comply with The Joint Commission's National Patient Safety Goals 9, "reduce the risk of patient harm resulting from falls" and to formulate evidence based best clinical practice recommendations on assessment and prevention of falls in the hospital for all inpatients, outpatients, customers and staffs within hospital premises. Materials and Methods: Contributing factors were identified based on the retrospective analysis of falls from 1st.January 2008 to 30th September 2008. A fall risk assessment tool identified as KPJ FRAT (KPJ Fall Risk Assessment Tool) for inpatient was developed and various other strategies to reduce the risk of falls throughout the hospital premises were identified. Points of engagement for inpatient assessment using KPJ FRAT were on admission, transfer in or when there is a change in patients' condition. A prospective descriptive study was done and data was collected from 1st January 2009 till 31st December 2009 through interview with patients, healthcare providers and review of adverse event reports and medical records. Results: No of inpatients during this study were 37058 and there were 13 falls. The post implementation data reflects for every 1000 inpatient days the fall rate decreased to 4.3 falls. Conclusion: The use of KPJ FRAT and Fall Prevention program implemented throughout KPJ SSH has reduced the incidence of falls significantly by $48 \%$. This might be due to increase awareness among the staff, hospital wide policy to report all cases and the formation of patient safety committee to formulate policy and reinforce the implementation processes. Limitation of the study include under reporting and heavy workload.
\end{abstract}

KEYWORDS: Risk, falls, inhospital

Corresponding author;

Asrina Asri, Physiotherapist, KPJ Seremban Specialist Hospital, Lot 6219 \& 6220, Jalan Toman Satu, Kemayan Square,

70200 Seremban, Negeri Sembilan

e-mail: asrina@ssh.kpjhealth.com.my 